\title{
The Design of Road Evaluation and Monitoring System based on Geographical Information System
}

\author{
Ary Setyawan ${ }^{1,}$, Muhammad Farid Al Alimi ${ }^{2}$, Dewi Handayani ${ }^{2}$, Agus Sumarsono ${ }^{1}$ \\ ${ }^{1}$ Roadmate Research Group, Universitas Sebelas Maret, Surakarta 57126, Indonesia \\ ${ }^{2}$ Civil Engineering Department, Universitas Sebelas Maret Surakarta 57126, Indonesia
}

\begin{abstract}
Road infrastructure that are suffered by high traffic volume and repetitive loading will lead to a decline in the quality and capacity. As an indicator can be seen from the road surface conditions, both structural and functional condition. Damage that occurs varies greatly along the road and when left in the long term, it will worsen the condition of the road. The method used in the evaluation of damage to roads in Indonesia is PCI ( Pavement Condition Index) method. PCI method is a method of road pavement condition assessment based on the type of damage, severity level and ethe density of damages compare to the wide of road surfacing. Application of PCI method tend to be less desirable because of the classification of the type of damage and the level of severity meausurement and density calculation are performed by manual observations at each segment and further calculation are still needed to get the index value. Road Evaluation and Monitoring System is a proposed system that lead to the adoption of Geographical Information Sistem based device to reduce the costs and labor for pavement evaluation and monitoring.
\end{abstract}

\section{Introduction}

Networks of road infrastructure in Indonesia are widely scattered. The whole road network requires evaluation and monitoring on a regular basis to determine the level of damage. Road manual evaluation and monitoring in all parts of Indonesian road require substantial resources, time consuming and expensive. For this reason, the tool is expected to facilitate this process of evaluation and monitoring that can be caried out faster, with less effort and cost. This study is proposed to design a tool named Road Evaluation and Monitoring System (REMS) to assist evaluation and monitoring road damage automatically. This design involves the use of various types of sensors and programs to assist in the detection of damage to the road as well as to input the data into Geographical Information System. Designing the REMS aims to perform evaluation and monitoring of road damage and expected to be significantly cheaper, faster and easier than the existing manual application [1].

*Corresponding author: arysetyawan@staff.uns.ac.id 


\section{Basic Technology for Development}

Standardized evaluation of the severity level on the road in this research is divided into two types, namely, IRI and PCI. IRI standards obtained by noting the level of roughness of the road along the road and the process to get the value of IRI. Standard PCI damage is obtained by detecting the damage and measure their density of damage against the dimensions, followed by processing the data to get their PCI values [2].

The level of road roughness can be accounted for by a variety of methods. The method used in this research is the accelerometer sensor. The accelerometer sensor can be used to measure the acceleration of gravity and changes in real time. Initially, the beginning of the study the testing of accelerometer sensors technology were conducted to understand their performances and limitations of these sensors by using Android smartphones. Android smartphone is now generally implanted accelerometer sensor for multi-purpose applications. The sensor works internally and follow the user behavior. To test the accelerometer sensor on the Android smartphone, a simple application is carried out to detect changes that occur in the value of existing sensors on smartphones.

\section{Hardware development and data flow}

Road Evaluation and Monitoring System technology consists of two major systems: hardware and software. The REMS hardware system is designed based on phase 1, consists of a variety of sensors that are used to support the evaluation process of road damage. Accelerometer sensors mounted on a vehicle survey consists of 2 pieces each of which is connected to the microcontroller. When the system is running, the gravitational acceleration data change at any time are recorded and sent via microcontroller to the Central Processing Unit (CPU). Figure 1 shows the data flow process. Odometer mounted on the vehicle serves as registrar distance that has been taken during the survey. This distance changes in real time and the distance data transmitted via microcontroller to CPU.

On the CPU, accelerometer data are processed based on data from the odometer distance to get a profile of the road. The IRI value obtained approximately 100 meters each survey. The GPS device mounted on a vehicle survey serves to capture the satellite signals of GPS and GLONASS constellation. The signal is then converted into position data and then transmitted via USB to the CPU.

The CPU itself is in the form of high-performance laptop computer capable of receiving input from all sensors at once and be able to quickly processed the existing data into the road damage data and send some data to the server via the internet. Data stored in the CP, is stored in the Data Logger in the form of NAS (Network Attached Storage). The NAS serves as the storage of data during the survey. NAS is connected to the CP through Gigabyte Ethernet network that allows fast access up to 1 Gbps. NAT allows a survey carried out for a long time and a large capacity file backup. CP connected with the HSPA modem capable of GSM mobile network connected to the Internet. This connection can then be used by the CP to send data to the server so that the monitoring process of the survey can be done [3].

CPU is connected to an LCD or Android Smartphone which serves as a tool to show the display of survey process, the condition of survey equipment and the data flow connection conditions as well as to control of the entire equipment survey.

The entire existing hardware requires electrical energy supplied from the battery. The batteries to supply the energy to the inverter and then from the inverter, the electrical energy adapted to the respective hardware so that the output can be directly connected to the associated hardware securely. Figure 2 shows the Road Evaluation and Monitoring System (REMS) initial design car. 


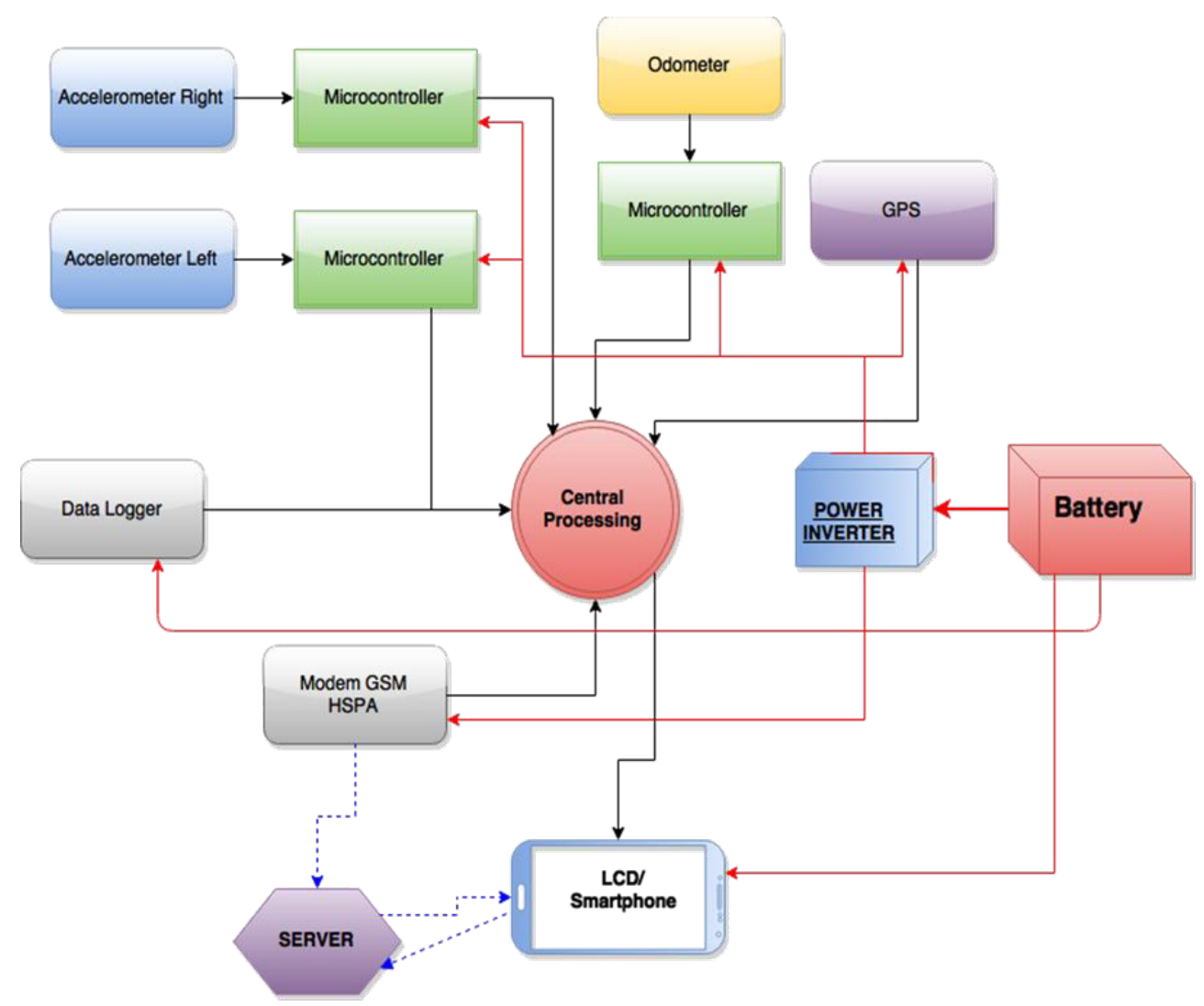

Fig. 1. Data flow process

\subsection{Sensor Design}

To detect the roughness of the road this study using the accelerometer sensor. Accelerometer sensor used is a 3- axis sensor. Sensor accelerometer has many types and specification according to the data requirements.

\subsection{Design of Syncronitation Method Based on Distance}

The output data from the accelerometer sensor must be associated with a distance that can be processed accurately. There are many methods for measuring the distances, such as GPS and odometer standard car, but the two are not able to provide the data range with accurate and fast output. Existing GPS has an error rate of about 3 meters. Car odometer measured with the smallest unit of $0.1 \mathrm{~km}$. So that both are not feasible to measure distances with high precision.

Therefore, in this study designed custom odometer mounted on the gearbox with high detail capability. This odometer uses laser technology and filter are rotated with one axle gearbox car. As car gearbox ratios angular velocity with the car so that the wheel angular velocity filters can be processed into the actual distance traveled by car survey. In theory odometer is able to detect the distance with great detail, but the accuracy is limited research to a range between $3-5 \mathrm{~cm}$. 


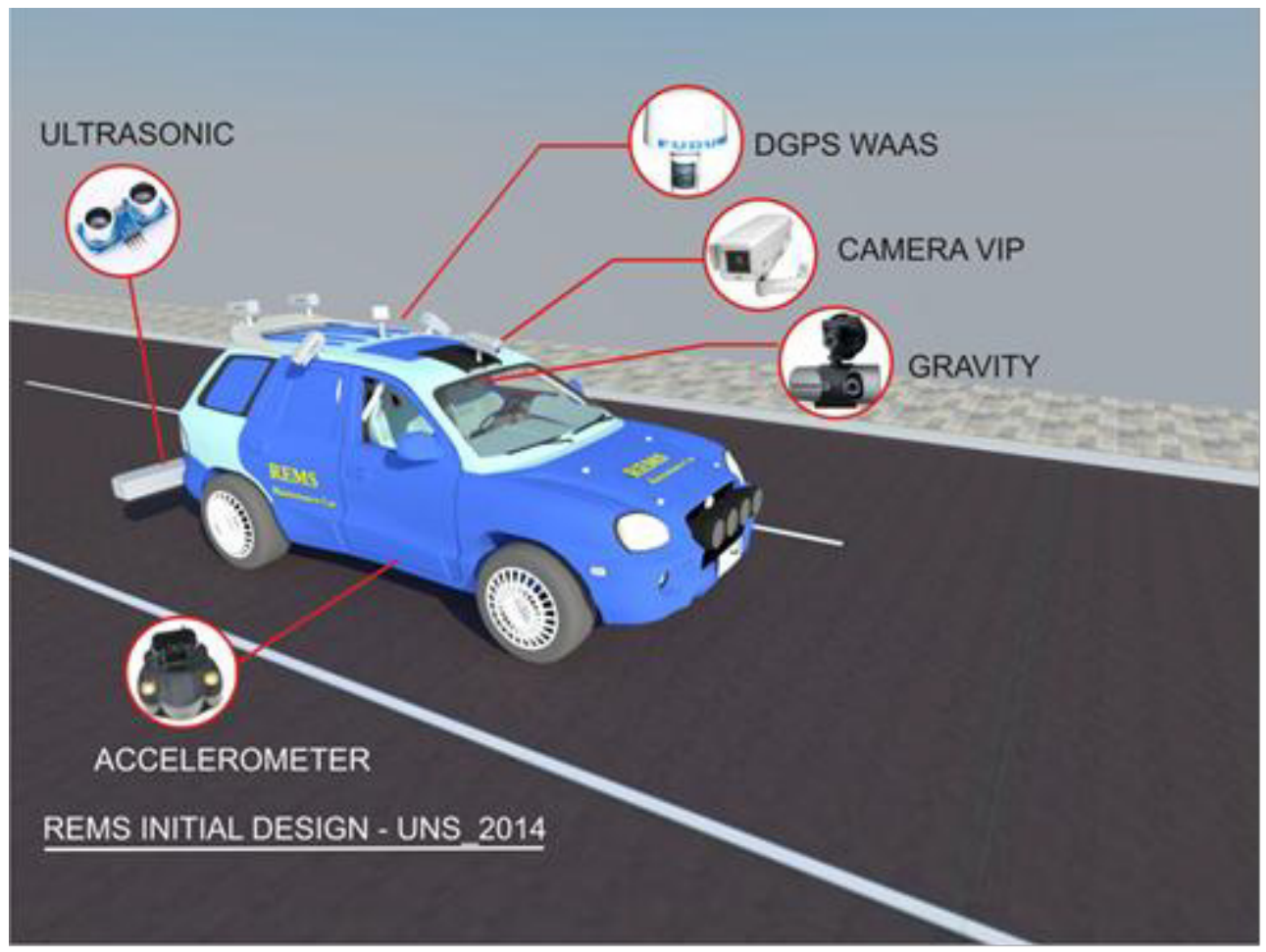

Fig. 2. Road Evaluation and Monitoring System (REMS) Initial Design

\subsection{Design of GIS Integration and Connectivity}

For connectivity and integration of GIS, GPS device uses the external antenna. Output GPS itself depends on the several factors, but in general the maximum output is $10 \mathrm{~Hz}$ GPS. The GPS output range is $0.1 \mathrm{~Hz}$ to $10 \mathrm{~Hz}$. In addition, the GPS can be set to output also influenced by the change in position, it means that if the vehicle position is not changed then the GPS survey does not provide output.

The data output from the GPS is stored into the database on the CPU and collected along with the other sensor data so that the other data can be integrated geographically. GPS data are also sent to the server along with most other data for remote monitoring survey vehicle. The data are sent to the server using GSM HSPA modem with updates within $0.1 \mathrm{~Hz}$ to $1 \mathrm{~Hz}$.

The position data is also transmitted from the CPU database to LCD or Android smartphone on the dashboard via a Bluetooth connection or the Internet. The position data can also be processed internally on a smartphone to facilitate the application by using the internal GPS sensor smartphone. The data required by the smartphone position to indicate the position, location, surveys progress and other data required by surveyors in the field.

\subsection{Profilometer Design}

Profilometer sensor consists of 15 pieces of high- speed laser distance to scan the road profile in the field. Lasers are used in the design is a Class 1 laser with the ability to scan up to $50 \mathrm{~Hz}[4,5]$. The relationship between the car speed laser scan survey and can be seen in Table 1. 
Table 1. Relationship between the car speed, laser scan survey and output profilometer

\begin{tabular}{cccccc}
\hline No. & $\begin{array}{c}\text { Speed } \\
(\mathrm{km} / \mathrm{hr})\end{array}$ & $\begin{array}{c}\text { Speed } \\
(\mathrm{m} / \mathrm{s})\end{array}$ & $\begin{array}{c}\text { Scan } \\
(\mathrm{Hz})\end{array}$ & $\begin{array}{c}\text { Interval } \\
(\mathrm{m})\end{array}$ & $\begin{array}{c}\text { Interval } \\
(\mathrm{cm})\end{array}$ \\
\hline 1 & 30 & 8.333333333 & 50 & 0.1666666667 & 16.66666667 \\
2 & 40 & 11.11111111 & 50 & 0.222222222 & 22.22222222 \\
3 & 50 & 13.88888889 & 50 & 0.2777777778 & 27.77777778 \\
4 & 60 & 16.66666667 & 50 & 0.333333333 & 33.33333333 \\
\hline
\end{tabular}

From Table 1, it can be seen that the lower the vehicle speed survey, the lower the interval between scans so the more accurate the results of the survey, however it need the longer time to conduct the survey. This problem could be solved by an interval of $20 \mathrm{~cm}$ to $27 \mathrm{~cm}$ and considered to be an ideal interval so that the car can run the surveys with an ideal speed and not exceed than $50 \mathrm{~km} /$ hour.

\subsection{Design of Visual Damage Detection Sensor}

The visual impairment in the form of visible damage to the eye is processed using computer vision technology with the sensor input of the camera. Because, it mounted on the running vehicle, then used a high-resolution camera sensor with a framerate of 30-60 fps [6,7]. Field of View is processed in the camera and set so that only the processing area with the transverse distance of 3.5 meters at a distance of 3 meters extending roads. The camera sensor mounted on balancer to reduce shacking or vibration that occurs when the survey is carryng out.

\section{Summary}

1. The schematic hardware of this REMS technology can be made and resolved

2. Design, implementation of road roughness using an accelerometer sensor, proximity sensor using a laser odometer, GPS sensor, camera sensor and profilometer sensor have been completed and ready to be implemented

3. Profilometer has a range of about $50 \mathrm{~Hz}$ and computer vision technology also has limitations in graphics processing so that the ideal speed survey is approximately 40 $\mathrm{Km} \mathrm{h}$

4. The accelerometer has a high output levels of $550 \mathrm{~Hz}$ so as to survey the damage only based IRI survey vehicle can drive up to $80 \mathrm{~km} / \mathrm{h}$

\section{References}

1. Direktorat Jendral Bina Marga, Indonesian Public Work Department (1998)

2. Ary Setyawan, Jolis Nainggolan, and Arif Budiarto, Procedia Engineering 125 :417423 (2015)

3. Wix Richard, and Roland Leschinski, International Public Works Conference, Darwin, Northern Territory, Australia (2013).

4. Bennett, Christopher R., and Hanqing Wang, Harmonising automated rut depth measurements. No. 242 (2003).

5. Huidrom, Lokeshwor, Lalit Kumar Das, and S. K. Sud, Procedia-Social and Behavioral Sciences : 312-321. 104 (2013) 
6. Ksaibati, Khaled, McNamara, Ronald and Armaghani, Jamshid. Department of Transportation State of Florida - Report (1999)

7. Ogonda, Godfrey Onyango, Recovery of the geometric road design elements using low-cost sensors: a feasibility study (2009). 